\title{
4-meter gait speed test as a tool to prescribe walking exercise intensity in individuals with COPD
}

Gianna Waldrich Bisca (1D; Andrea Akemi Morita ${ }^{1}$ (D); Felipe Vilaça Cavallari Machado ${ }^{1}$ (1); Antenor Rodrigues $^{1}$ (D); Thais Sant'Anna ${ }^{1}$ (D); Nidia Aparecida Hernandes ${ }^{1}$ (D); Fabio Pitta ${ }^{1 *}$ (D).

\author{
How to cite \\ Bisca GW, Morita AA, Machado FVC, Rodrigues A, Sant'Anna T, Hernandes NA, et al. \\ 4-meter gait speed test as a tool to prescribe walking exercise intensity in individuals \\ with COPD. Cardiorespir Physiother Crit Care Rehabil. 2021;1:e42316. https://doi. \\ org/10.4322/2675-9977.cpcr.42316
}

\section{Introduction}

Exercise training remains the essential component of rehabilitation programs in individuals with chronic obstructive pulmonary disease (COPD) ${ }^{1}$. In order to guarantee the training benefits, an appropriate prescription of exercise intensity is necessary ${ }^{1}$. The target intensity for training is generally prescribed as a percentage of maximum exercise capacity ${ }^{1}$; however, a simple field test such as the 6-minute walking test (6MWT) was shown to be useful in exercise prescription for walking ${ }^{2-4}$.

The importance of the 6MWT to evaluate exercise capacity is undeniable ${ }^{5}$; nevertheless, the test requires space and time, which may hinder its use in home visits and in some clinical settings. On the other hand, the 4-meter gait speed (4MGS) is a reliable test, which requires short time and space ${ }^{6-9}$. It reflects global well-being and captures the multisystemic effects of disease severity ${ }^{9}$. Furthermore, walking is the main activity in a rehabilitation program and gait speed measure is modifiable through rehabilitation, therefore being a potential marker of functional improvement or decline ${ }^{8-9}$.

Although the 4MGS has potential as an assessment tool, further work is necessary to confirm its utilization for exercise prescription. Therefore, the aims of this study were to verify whether it is possible to prescribe the intensity of walking exercise training and to predict the distance covered in the 6MWT through the 4MGS in individuals with moderate-to-very severe COPD. In addition, since there are different available protocols for the 4MGS, another aim was to identify which protocol better estimates these outcomes.

\section{Methods}

In this cross-sectional study, 44 individuals were submitted to assessments of lung function, performed according to international guidelines ${ }^{10}$, and functional exercise capacity. The study was approved by the Research Ethics Committee of the University Hospital, State University of Londrina, Brazil (080/2014), all individuals signed a written informed consent and the manuscript is presented according to the STROBE guidelines.

A convenience sample was composed by individuals with the diagnosis of COPD according to Global Initiative for Chronic Obstructive Lung Disease (GOLD ${ }^{11}$ criteria, absence of exacerbations within the previous 3 months and not having attended a pulmonary rehabilitation program in the last year. Subjects were excluded if they had any comorbidity that might have influenced the execution of the tests or if, for any reason, they were unable to perform the proposed activities.

\footnotetext{
Submitted: December 17, 2020.

Accepted: July 07, 2021.

Study conducted at: Universidade Estadual de Londrina, Londrina, Paraná, Brazil. Ethical approval: The study was approved by the Research Ethics Committee of the University Hospital, State University of

Londrina, Brazil (080/2014).

Universidade Estadual de Londrina - UEL, *Correspondi
Fabio Pitta

86038-350 Londrina (PR) Brasil

Tel: +55 (43) 3371-2477
} 
Six-minute walk test: The 6MWT was performed in accordance with international standards ${ }^{5}$ and Brazilian normal values were used ${ }^{12}$. Each subject performed two tests and the test with longer walked distance $\left(6 \mathrm{MWT}_{\text {distance }}\right)$ was considered for analysis. The exercise intensity criteria was set at $75 \%$ of the $6 \mathrm{MWT}$ average speed $\left(6 \mathrm{MWT}_{75 \% \text { speed }}\right)^{3}$, and the $6 \mathrm{MWT}$ speed was calculated as the walked distance (in meters) divided by the time (in seconds).

Gait speed ${ }^{6,7}$ : Individuals were instructed to walk in a 4-meter course hallway and a stopwatch was used to record the time taken to complete the course. All individuals were submitted to four different protocols of the 4MGS (4MGS4U; 4MGS-4M; 4MGS-8U; 4MGS-8M, as described below) in a randomized sequence. Each protocol was repeated twice without rest and the faster of the two tests was used to calculate the speed (in $\mathrm{m} / \mathrm{s}$ ).

$4 M G S-4$ (static start): Two cones were placed 4 meters apart and the participant was positioned slightly behind the first cone. Timing with the stopwatch started when the participant began to move and was stopped when the participant's first foot completely crossed the second cone. Individuals were instructed to walk at the usual (4MGS-4U) and maximum (4MGS-4M) speed.

$4 M G S-8$ (rolling start): It was performed in an 8-meter course (a 2-meter acceleration zone, a 4-meter timing area and a 2-meter deceleration zone) and the gait speed in the central 4 meters of the corridor was evaluated. The timing started when the participant's first foot completely crossed the start of the 4-meter timing area and stopped when the participant's first foot completely left this area. The instructed pace was also usual (4MGS-8U) and maximum (4MGS-8M) speed.

The statistical analysis was performed using the statistical software packages SPSS 21.0 (SPSS Inc., USA) and GraphPad Prism 6.0 (GraphPad Software Inc., USA). The normality of data distribution was checked by the Shapiro-Wilk test and described as mean $\pm \mathrm{SD}$ or median [interquartile range]. Paired $t$ test was used to compare 4MGS and 6MWT Pearson correlation coefficients were calculated and models of univariate linear regression were applied with $6 \mathrm{MWT}_{\text {distance }}$ and $6 \mathrm{MWT}_{75 \% \text { speed }}$ as dependent variables, and the $4 \mathrm{MGS}$ protocols as independent variables.

In order to verify the reliability of the regression equation, the formula developed in this study was applied a posteriori in a validation sample $(\mathrm{n}=12)$ composed by different individuals with COPD (not included in the first analysis). These individuals were selected according to the same inclusion criteria of the first sample. The Intraclass Correlation Coefficient (ICC) was used to evaluate agreement between the actual $6 \mathrm{MWT}_{75 \% \text { speed }}$ and the predicted values. $P<0.05$ was set as statistical significance.

\section{Results}

The characteristics of 44 individuals with COPD are described in Table 1. The gait speed varied among the 4MGS protocols and the highest speed was achieved in the 4MGS-
$8 \mathrm{M}$ protocol (Table 1). The speed achieved in all 4MGS protocols was higher than $6 \mathrm{MWT}_{75 \% \text { speed }}(P<0.01$ for all $)$.

Significant correlations were found between $6 \mathrm{MWT}_{75 \% \text { speed }}$ with all $4 \mathrm{MGS}$ protocols $(0.47 \leq \mathrm{r} \leq 0.69$, see Table 2). There were also significant correlations between $6 \mathrm{MWT}_{\text {distance }}$ with $4 \mathrm{MGS}-4 \mathrm{M}, 4 \mathrm{MGS}-8 \mathrm{U}$ and $4 \mathrm{MGS}-8 \mathrm{M}$, $(0.40 \leq \mathrm{r} \leq 0.49$, see Table 2$)$. The coefficients of determination values are described in Table 2. $6 \mathrm{MWT}_{\text {distance }}$ could not be estimated satisfactorily by any of the 4MGS protocols. On the other hand, a model of univariate linear regression showed that the 4MGS-8M predicted $6 \mathrm{MWT}_{75 \% \text { speed }}$, explaining $46 \%$ of its variability $(P<0.0001)$ (Figure 1). According to $4 \mathrm{MGS}-8 \mathrm{M}$, the reference equation for the $6 \mathrm{MWT}_{75 \% \text { speed }}$ was:

$6 M W T_{75 \% \text { speed }}$ (in m/s) $=[0.407+(0.329 * 4 M G S-8 M)]$

The characteristics of the validation sample composed by 12 individuals with COPD (6 male) included in the $a$ posteriori analysis were: age $68 \pm 7$ years, BMI $27 \pm 4 \mathrm{~kg} / \mathrm{m}^{2}$, $\mathrm{FEV}_{1} 57 \pm 17 \%$ pred and $\mathrm{FEV}_{1} / \mathrm{FVC}$ ratio $57 \pm 11 \%$ pred. When the reference equation for the $6 \mathrm{MWT}_{75 \% \text { speed }}$ derived from the 4MGS-8M was applied in this validation sample, there was good agreement between the actual $6 \mathrm{MWT}_{75 \% \text { speed }}(0.99 \pm 0.11 \mathrm{~m} / \mathrm{s})$ and the predicted $6 \mathrm{MWT}_{75 \% \text { speed }}(0.98 \pm 0.11 \mathrm{~m} / \mathrm{s})$ obtained from the reference equation ( $\mathrm{ICC}=0.80$ ). No difference between the actual and predicted $6 \mathrm{MWT}_{75 \% \text { speed }}$ was found $(P=0.81)$ and there was moderate correlation between them $(\mathrm{r}=0.63)$.

Table 1. Characteristics of sample of the individuals with COPD.

\begin{tabular}{|c|c|}
\hline & $\mathrm{n}=44$ \\
\hline $\operatorname{Sex}(M / F)$ & $24 / 20$ \\
\hline Age (years) & $69 \pm 8$ \\
\hline BMI $\left(\mathrm{kg} \cdot \mathrm{m}^{-2}\right)$ & $25[22-30]$ \\
\hline $\mathrm{FEV}_{1}(\mathrm{~L})$ & $1.25 \pm 0.45$ \\
\hline $\mathrm{FEV}_{1}(\%$ predicted $)$ & $49 \pm 18$ \\
\hline $\mathrm{FEV}_{1} / \mathrm{FVC}(\%)$ & $53 \pm 12$ \\
\hline GOLD (II/III/IV) & $23 / 15 / 6$ \\
\hline $6 \mathrm{MWT}_{\text {Distance }}(\mathrm{m})$ & $453 \pm 73$ \\
\hline $6 \mathrm{MWT}$ (\%predicted) & $85 \pm 15$ \\
\hline $6 \mathrm{MWT}_{\text {speed }}(\mathrm{m} / \mathrm{s})$ & $1.28 \pm 0.20$ \\
\hline $6 \mathrm{MWT}_{75 \% \text { speed }}(\mathrm{m} / \mathrm{s})$ & $0.96 \pm 0.15$ \\
\hline 4MGS-4U(m/s) & $1.05 \pm 0.23$ \\
\hline $4 \mathrm{MGS}-4 \mathrm{M}(\mathrm{m} / \mathrm{s})$ & $1.38 \pm 0.24$ \\
\hline $4 \mathrm{MGS}-8 \mathrm{U}(\mathrm{m} / \mathrm{s})$ & $1.29 \pm 0.23$ \\
\hline 4MGS-8M (m/s) & $1.68 \pm 0.31$ \\
\hline
\end{tabular}

Data expressed as absolute frequency, mean \pm SD or median [IQR]. M: male; F: female; BMI: body mass index; $\mathrm{FEV}_{1}$ : forced expiratory volume in the first second; $\mathrm{FVC}$ : forced vital capacity; GOLD: Global Initiative for Chronic Obstructive Lung Disease; $6 \mathrm{MWT}_{75 \% \text { speed }}: 75 \%$ of the six-minute walk test average speed; $6 \mathrm{MWT}_{\text {Distance }}:$ distance walked in the six-minute walk test; 4MGS-4U: four-meter gait speed at the usual speed in a 4-meter course; 4MGS-4M: four-meter gait speed at the maximal speed in a 4-meter course; 4MGS-8U: four-meter gait speed at the usual speed in an 8-meter course; 4MGS-8M: four-meter gait speed at the maximal speed in an 8-meter course. 
Table 2. Pearson correlation coefficients and coefficients of determination of the four 4MGS protocols with walking exercise intensity and the distance covered in the 6MWT as dependent variables.

\begin{tabular}{|c|c|c|c|c|}
\hline Protocol & r 6MWT ${ }_{75 \% \text { speed }}$ & r 6MWT ${ }_{\text {Distance }}$ & $\mathrm{R}^{2} 6 \mathrm{MWT}_{75 \% \text { speed }}$ & $\mathrm{R}^{2} 6 \mathrm{MWT}_{\text {Distance }}$ \\
\hline 4MGS-4U & 0.47 & $0.28 *$ & 0.20 & 0.06 \\
\hline 4MGS-4M & 0.63 & 0.46 & 0.38 & 0.19 \\
\hline 4MGS-8U & 0.59 & 0.40 & 0.33 & 0.14 \\
\hline 4MGS-8M & 0.69 & 0.49 & 0.46 & 0.23 \\
\hline
\end{tabular}

6MWT75\%speed: 75\% of the six-minute walk test average speed; 6MWTDistance: distance walked in the six-minute walk test. 4MGS-4U: four-meter gait speed at the usual speed in a 4-meter course; 4MGS-4M: four-meter gait speed at the maximal speed in a 4-meter course; 4MGS-8U: four-meter gait speed at the usual speed in an 8-meter course; 4MGS-8M: four-meter gait speed at the maximal speed in an 8 -meter course; ${ }^{*} P=0.06$.

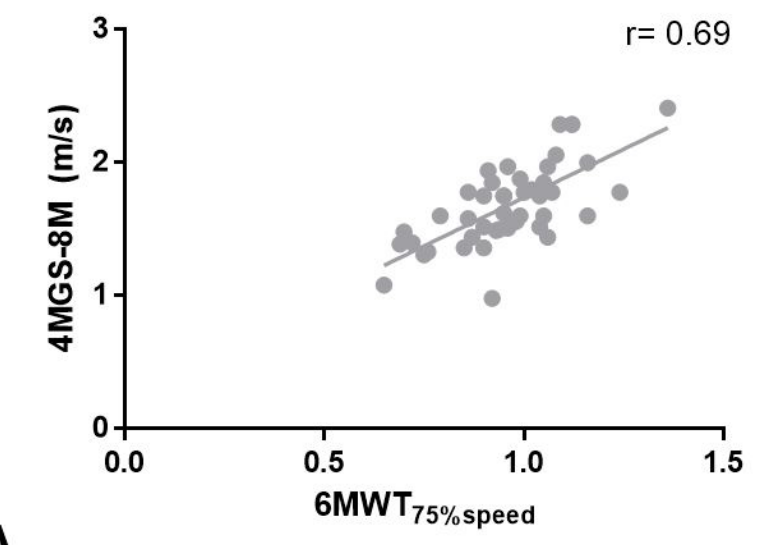

A

Figure 1. Correlation between 4MGS-8M and 6MWT (A: 75\% of the average speed; and B: distance walked; $P \leq 0.001 \mathrm{for}$ both). $6 \mathrm{MWT}$ : six-minute walk test; 4MGS-8M: four-meter gait speed at the maximal speed in an 8-meter course.

\section{Discussion}

Although the 4MGS can be used as an assessment tool of physical function in individuals with $\mathrm{COPD}^{6-9}$, to the authors' best knowledge this is the first study to assess its capacity to prescribe exercise. In addition, the findings were extended to different 4MGS measurement protocols. Among the four studied protocols, the $4 \mathrm{MGS}$ performed at maximum speed in an 8-meter corridor seems to be a suitable option to prescribe walking exercise intensity for individuals with COPD. The present results also demonstrated that these four studied protocols were not able to properly predict the distance achieved in the 6MWT.

Although the 6MWT has a submaximal profile, it can be used to prescribe walking exercise intensity since it provides sufficient physiological stress in individuals with $\mathrm{COPD}^{2}$. Responses concerning maximal oxygen consumption $\left(\mathrm{VO}_{2} \mathrm{max}\right)$ are similar during the execution of the 6MWT and during the cardiopulmonary exercise test $(\mathrm{CPET})^{13}$. Although the 4MGS provides less physiological information and was not able to identify the need for oxygen supplementation when compared to the $6 \mathrm{MWT}^{14}$, it was applicable to prescribe walking exercise training intensity in an easy-to-perform way. Furthermore, in accordance with previous studies ${ }^{6,15,16}$, the present study also found a significant association between gait speed and exercise capacity.

Simple functional tests which simulate everyday tasks and involve basic movements are increasingly used in clinical practice $^{14}$ and the literature should focus more deeply in the understanding of some gaps regarding these tests. Meaningful information can come from the use of gait speed tests for chronic respiratory diseases, more than just the speed of the tes $\mathrm{t}^{17}$. For instance, it can also be used as a screening tool for exercise intolerance ${ }^{6,9}$, as an outcome measure for frail individuals ${ }^{6,9}$ and even as an indicator that predicts end of life in $\mathrm{COPD}^{17}$. Moreover, the $4 \mathrm{MGS}$ offers some advantages in daily practice since it does not require a special place to be performed (e.g., 30-meter corridor), has a short administration time and requires simple and low cost equipment ${ }^{6,7,14}$.

Gait speed measurements are reliable in individuals with COPD regardless of the instructed pace and distance ${ }^{7}$; however, according to the present results, walking exercise intensity can be better explained by the 4MGS-8M protocol. This discrepancy happens because a greater number of steps and a rolling start in the test might be more accurate for estimating gait speed ${ }^{18}$. A static start in short distances can result in slower speed ${ }^{18}$. None of the protocols could explain more than $23 \%$ of $6 \mathrm{MWT}_{\text {distance }}$, and this is likely because speed and distance have different constructs. Therefore, the $4 \mathrm{MGS}$ does not predict well the $6 \mathrm{MWT}_{\text {distance }}$ and cannot replace it, although it seems to provide a feasible way to prescribe walking exercise.

Despite all efforts, the present study has limitations. The use of a convenience sample, with no individuals classified as GOLD I, restricts the results to individuals with moderate-to- 
very severe degree of airflow obstruction. Moreover, no oxygen consumption analysis was performed. Larger studies could provide more robust prediction models. Furthermore, future studies should investigate whether using the 4MGS for walking exercise intensity prescription is able to lead to clinically significant improvements after pulmonary rehabilitation.

In conclusion, the clinical usefulness of the 4MGS may be larger than previously expected since all 4MGS protocols are significantly associated with 6MWT. Furthermore, the 4MGS at the maximum speed in a corridor of 8 meters proved to be the best option in the prescription of walking exercise intensity for individuals with moderate-to-very severe COPD.

\section{Funding}

There was no specific funding for the study. However, all authors were/are supported by individual grants from $\mathrm{CNPq}$ or CAPES, Brazil.

\section{Conflict of interest}

None.

\section{Acknowledgements}

The authors would like to thank the colleagues of LFIP for their contribution to the study.

\section{References}

1. Spruit MA, Singh SJ, Garvey C, ZuWallack R, Nici L, Rochester C, et al. An official American Thoracic Society/European Respiratory Society statement: key concepts and advances in pulmonary rehabilitation. Am J Respir Crit Care Med. 2013; 188(8):e13-e64. Available from: https:// www.atsjournals.org/doi/pdf/10.1164/rccm.201309-1634ST.

2. Zainuldin R, Mackey MG, Alison JA. Prescription of walking exercise intensity from the 6-minute walk test in people with chronic obstructive pulmonary disease. J Cardiopulm Rehabil Prev. 2015;35(1):65-9. http:// dx.doi.org/10.1097/HCR.0000000000000074. PMid:24983708.

3. Probst VS, Kovelis D, Hernandes NA, Camillo CA, Cavalheri V, Pitta F. Effects of 2 exercise training programs on physical activity in daily life in patients with COPD. Respir Care. 2011;56(11):1799-807. http:// dx.doi.org/10.4187/respcare.01110. PMid:22035826.

4. Rodrigues A, Di Martino M, Nellessen AG, Hernandes NA, Neder JA, Pitta F. Is the six-minute walk test a useful tool to prescribe highintensity exercise in patients with chronic obstructive pulmonary disease? Heart Lung. 2016;45(6):550-6. http://dx.doi.org/10.1016/j. hrtlng.2016.08.005. PMid:27639286.

5. Holland AE, Spruit MA, Troosters T, Puhan MA, Pepin V, Saey D, et al. An official European Respiratory Society/American Thoracic Society technical standard: field walking tests in chronic respiratory disease. Eur Respir J. 2014;44(6):1428-46. http://dx.doi. org/10.1183/09031936.00150314. PMid:25359355.
6. Kon SS, Patel MS, Canavan JL, Clark AL, Jones SE, Nolan CM, et al. Reliability and validity of 4-metre gait speed in COPD. Eur Respir J. 2013;42(2):333-40. http://dx.doi.org/10.1183/09031936.00162712. PMid:23222875.

7. Karpman C, Lebrasseur NK, Depew ZS, Novotny PJ, Benzo RP. Measuring gait speed in the out-patient clinic: methodology and feasibility. Respir Care. 2014;59(4):531-7. http://dx.doi.org/10.4187/ respcare.02688. PMid:23983271.

8. Kon SS, Canavan JL, Nolan CM, Clark AL, Jones SE, Cullinan P, et al. The 4-metre gait speed in COPD: responsiveness and minimal clinically important difference. Eur Respir J. 2014;43(5):1298-305. http://dx.doi. org/10.1183/09031936.00088113. PMid:24177002.

9. Karpman C, Benzo R. Gait speed as a measure of functional status in COPD patients. Int J Chron Obstruct Pulmon Dis. 2014;9:1315-20. PMid:25473277.

10. Miller MR, Crapo R, Hankinson J, Brusasco V, Burgos F, Casaburi $\mathrm{R}$, et al. General considerations for lung function testing. Eur Respir J. 2005;26(1):153-61. http://dx.doi.org/10.1183/09031936.05.000345 05. PMid:15994402.

11. GOLD: Global strategy for the diagnosis, management and prevention for chronic obstructive pulmonary disease [Internet]. 2016 [cited 2016 June 10]. Available from: www.goldcopd.org.

12. Britto RR, Probst VS, Andrade AFD, Samora GA, Hernandes NA, Marinho PE, et al. Reference equations for the six-minute walk distance based on a Brazilian multicenter study. Braz J Phys Ther. 2013;17(6):556-63. http://dx.doi.org/10.1590/S141335552012005000122. PMid:24271092.

13. Troosters T, Vilaro J, Rabinovich R, Casas A, Barbera JA, RodriguezRoisin R, et al. Physiological responses to the 6-min walk test in patients with chronic obstructive pulmonary disease. Eur Respir J. 2002;20(3):564-9. http://dx.doi.org/10.1183/09031936.02.02092001 . PMid:12358329.

14. Bisca GW, Morita AA, Hernandes NA, Probst VS, Pitta F. Simple lower limb functional tests in patients with chronic obstructive pulmonary disease: a systematic review. Arch Phys Med Rehabil. 2015;96(12):2221-30. http://dx.doi.org/10.1016/j.apmr.2015.07.017. PMid:26254951.

15. DePew ZS, Karpman C, Novotny PJ, Benzo RP. Correlations between gait speed, 6-minute walk distance, physical activity, and self-efficacy in patients with severe chronic lung disease. Respir Care. 2013;58(12):2113-9. http://dx.doi.org/10.4187/respcare.02471. PMid:23696689.

16. Karpman C, DePew ZS, LeBrasseur NK, Novotny PJ, Benzo RP. Determinants of gait speed in COPD. Chest. 2014;146(1):104-10. http://dx.doi.org/10.1378/chest.13-2017. PMid:24522522.

17. Benzo R, Siemion W, Novotny P, Sternberg A, Kaplan RM, Ries A, et al. Factors to inform clinicians about the end of life in severe chronic obstructive pulmonary disease. J Pain Symptom Manage. 2013;46(4):491-9. http://dx.doi.org/10.1016/j. jpainsymman.2012.10.283. PMid:23522520.

18. Rozenberg D, Dolmage TE, Evans RA, Goldstein RS. Repeatability of usual and fast walking speeds in patients with chronic obstructive pulmonary disease. J Cardiopulm Rehabil Prev. 2014;34(5):348-54. http://dx.doi.org/10.1097/HCR.0000000000000072. PMid:24918352. 


\section{Author contributions}

GWB and FP had full access to the data and take responsibility as guarantors for the integrity of the data and the accuracy of the analysis and conclusions; GWB, AAM, FVCM, and AR made substantial contributions to the conception or design of the work. All authors contributed substantially to the acquisition, analysis or interpretation of data for the work and provided final approval of the article.

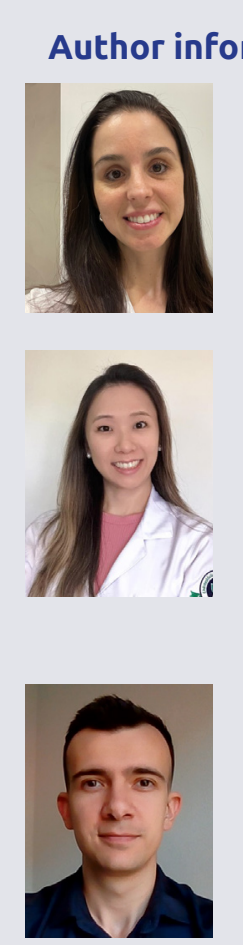

\section{Gianna Waldrich Bisca}

- Graduated in Physiotherapy, Universidade Estadual de Londrina, Brazil

- PhD in Rehabilitation Sciences UEL/UNOPAR, Londrina, Brazil

- Professor, Department of Physiotherapy, Centro Universitário Filadélfia, Brazil

\section{Andrea Morita}

- Graduated in Physiotherapy, Universidade Estadual de Londrina, Brazil

- MSc in Rehabilitation Sciences UEL/UNOPAR, Londrina, Brazil - PhD student in Rehabilitation Sciences UEL/UNOPAR, Londrina, Brazil

- Professor, Department of Physiotherapy, Centro Universitário Filadélfia, Brazil

\section{Felipe V. C. Machado}

- Graduated in Physiotherapy, Universidade Estadual de Londrina, Brazil

- Specialization (Postgraduate Course) in Physiology, Universidade Estadual de Londrina, Brazil

- MSc in Rehabilitation Sciences UEL/UNOPAR, Londrina, Brazil

- PhD student at the Faculty of Health, Medicine and Life Sciences (FHML) / Maastricht UMC+, Maastricht University, the Netherlands.

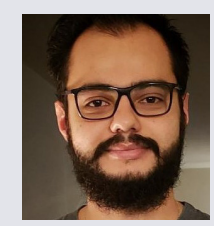

\section{Antenor Rodrigues}

- Graduated in Physiotherapy, Centro Universitário Filadélfia, Brazil - PhD in Rehabilitation Sciences UEL/UNOPAR, Londrina, Brazil - Post-doc fellow, Department of Critical Care, St. Michaels Hospital, Toronto, Canada.

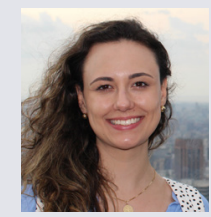

\section{Thaís Sant'Anna}

- Graduated in Physiotherapy, Universidade Estadual de Londrina, Brazil.

- PhD in Health Sciences, Universidade Estadual de Londrina, Brazil. - Adjunct Professor, Faculty of Physical Education and Physiotherapy, Universidade Federal do Amazonas, Brazil.

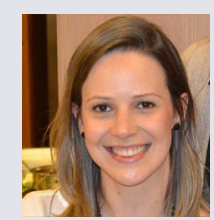

\section{Nidia Aparecida Hernandes}

- Graduated in Physiotherapy, Universidade Estadual do Oeste do Paraná, Brazil.

- PhD in Health Sciences, Universidade Estadual de Londrina, Brazil. - Associate Professor, Department of Physiotherapy, Universidade Estadual de Londrina, Brazil.

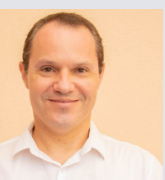

\section{Fabio Pitta}

- Graduated in Physiotherapy, Universidade Estadual de Londrina, Brazil. - PhD in Rehabilitation Sciences, Katholieke Universiteit Leuven, Belgium.

- Associate Professor, Department of Physiotherapy, Universidade Estadual de Londrina, Brazil. 